\title{
FORMULASI TABLET FUROSEMIDA DENGAN PENAMBAHAN PVP SEBAGAI ZAT PEMBENTUK KOMPLEKS TERHADAP SIFAT FISIK TABLET
}

\author{
${ }^{1}$ Dedy Frianto \\ ${ }^{2}$ Iin Lidia Putama Mursal \\ ${ }^{1}$ Prodi Farmasi Fakultas Teknologi dan Ilmu Komputer Universitas Buana Perjuangan \\ Karawang (dedyfrianto@ubpkarawang.ac.id) \\ ${ }^{1}$ Universitas Buana Perjuangan Karawang (iin.lidia@ubpkarawang.ac.id)
}

\begin{abstract}
ABSTRAK
Furosemida merupakan diuretik golongan sulfonamida yang praktis tidak larut dalam air dan mempunyai ketersediaan hayati yang kurang baik. Pada penelitian sebelumnya pembentukan kompleks furosemida dengan (PVP) meningkatkan disolusi dan ketersediaan hayati furosemida secara bermakna $(\mathrm{P}<0,05)$. Oleh karena itu perlu dilakukan penelitian tentang bagaimana formulasi untuk pembuatan tablet furosemida yang dibuat dari kompleks furosemida-PVP. Tablet furosemida-PVP dibuat dengan metode granulasi basah. Masing-masing formula memiliki kadar PVP yang bervariasi, pada formula II $25 \%$ dan formula III $50 \%$ dari zat aktifnya yaitu furosemida, formula I sebagai kontrol dipakai tablet furosemida ${ }^{\circledR}$. Pada formula II dan III dilakukan uji sifat fisik granul, serta uji sifat fisik tablet dan uji disolusi untuk semua formula. Hasil uji sifat fisik tablet dan uji disolusi diuji statistik menggunakan perangkat lunak SPSS. Hasil uji sifat alir granul untuk setiap formula memiliki waktu alir kurang dari 10 detik dan sudut diamnya kurang dari $42^{\circ}$ sehingga memiliki sifat alir granul yang baik. Uji sifat fisik tablet diperoleh hasil yang memenuhi syarat.
\end{abstract}

Kata kunci : Furosemida, Kelarutan, Kompleksasi, Disolusi

\section{ABSTRACT}

Furosemide is a diuretic sulfonamid groups which not in soluble practically and has poor bioavalaibility. The research of complex formation between furosemide and PVP increased the dissolution and bioavalaibility significantly with $95 \%$ reliable level. The interaction of furosemide-PVP complex were determined by infrared spectrum which show the string of functional compounds couse by complecxation. The tablet of furosemide-PVP made by wet granulation. Each formulas consist of various contain of PVP as carrier. On formula II $25 \%$ and formula III $50 \%$ from its active compound that is furosemide, formula I use as control. Each formulas II and III were evaluated its physical properties of granules and physical properties evaluation of tablet. Statistic done by SPSS. The result of flow properties of granules test for each formulas has flow time less than 10 second and the repose of angle were less than $42^{\circ}$ it concluded that is has good flow properties. From physical properties test resulted were fulfill the requirements.

Keywords : Furosemide, soluble, Complecxation, Dissolution 


\section{Pendahuluan}

Furosemida merupakan salah satu obat yang berfungsi sebagai diuretik atau peluruh air seni. Banyak sekali jenis obat peluruh air seni dan salah satu yang cukup populer adalah furosemida, dalam perdagangan terkenal produk patennya yaitu Lasix®. Furosemida merupakan obat diuretik turunan sulfonamida yang praktis tidak larut dalam air ini berarti bahwa profil disolusi dari tablet furosemida itu sendiri buruk dan dalam pustaka dilaporkan mempunyai ketersediaan hayati yang kurang baik.

Obat-obat yang kelarutannya kecil dalam air merupakan suatu problem dalam industri farmasi. Berbagai pendekatan telah dilakukan untuk meningkatkan kelarutan, kecepatan disolusi dan ketersediaan hayati suatu obat. Salah satunya dengan teknologi dispersi padat yang pernah dilaporkan memberikan hasil yang baik. Dengan dispersi padat bahan obat yang sukar larut dalam air akan didispersikan dalam suatu matrik yang mudah larut sehingga akan mengurangi ukuran partikel, sehingga memungkinkan terjadinya kompleksasi dan polimorfi yang lebih mudah larut. Peristiwa ini akan dapat meningkatkan kelarutan, mempercepat proses disolusi dan meningkatkan ketersediaan hayati suatu obat. Polivinilpirolidon (PVP) merupakan pembawa stabil yang larut dalam air dan telah banyak digunakan sebagai pembawa dalam dispersi padat (Chiou dan Riegelman, 1971).

Akbuga et al melaporkan bahwa sistem dispersi padat furosemida PVP dengan perbandingan 1:7 memberikan profil disolusi yang paling baik. Pengaruh dari berat molekul PVP terhadap laju disolusi furosemida dilaporkan bahwa PVP dengan berat molekul 49.000 (K-30) memberikan hasil yang terbaik dibanding dengan berat molekul 25.000 (K-25) dan 110.000 (K-90) Penelitian ini lalu dilanjutkan oleh Syukri pada tahun 2001 yang menyimpulkan bahwa pembentukan kompleks furosemida-PVP dapat meningkatkan disolusi furosemida secara signifikan $(\mathrm{P}<0,05)$, tetapi menyebabkan perpanjangan waktu awal pelepasan furosemida, hal ini disebabkan oleh terbentuknya gel akibat dispersi padat menghalangi difusi. ( cit. Syukri, 2001).

Berdasarkan penelitian tersebut di atas maka perlu dilakukan penelitian lanjutan mengenai formulasi tablet furosemida-PVP. 
Dengan adanya penelitian ini diharapkan akan diperoleh suatu formulasi tablet furosemida-PVP yang baik dan dapat menghasilkan tablet furosemida dengan sifat fisik yang baik sehingga efek farmakologis yang ditimbulkan juga jauh lebih maksimal.

\section{Metode Penelitian}

Alat

Alat-alat yang digunakan dalam penelitian ini adalah: alat-alat gelas, mesin cetak tablet single punch (Kikusui No-2-A,Kyoto), lemari pengering (Erweka), spektrofotometri UV (Shimadzu,1601 PC), FTIR (Digilab), ayakan (Endecotts), roche friabilator (Erweka), Stokes monsanto hardness tester (Hoshinos Jule), disintegrator, Stopwatch, Neraca analitik (Metler Toledo AG 283), seperangkat alat pengukur sifat alir granul.

Bahan

Bahan-bahan yang digunakan dalam penelitian ini meliputi: serbuk furosemida, PVP K30 (Polivinilpirolidon), amilum manihot, talkum venetum, laktosa, magnesium stearat (masing-masing dengan derajat farmasetis), metanol, alkohol 96\%, $\mathrm{NaOH}$, aquadestilata, larutan kalium fosfat pro analisis (E Merck). Sebagai pembanding digunakan tablet Furosemide $^{\circledR}$ (Generik).

\section{Pembuatan Dispersi Padat}

Serbuk dispersi padat furosemida-PVP dibuat dengan perbandingan $40 \mathrm{mg}$ furosemida dan PVP masing-masing $10 \mathrm{mg}$ dan $20 \mathrm{mg}$.

a. Pembuatan sistem dispersi padat

Dispersi padat furosemida-PVP dibuat dengan metode pelarutan, dengan melarutkan kedua zat menggunakan metanol sebagai pelarut hingga tepat larut, segera diuapkan pelarutnya dengan cepat pada suhu $<50^{\circ} \mathrm{C}$ diatas penangas air sambil diaduk dan diangin-anginkan, furosemida dan PVP ditimbang sesuai perbandingan formula, lalu digerus halus hingga homogen kemudian dilewatkan pada ayakan mesh no. 40/60. Kemudian sebelum dibuat tablet, kompleks diuji terlebih dahulu menggunakan FTIR, dengan cara mengukur serapan furosemida tunggal, PVP tunggal, dispersi padat furosemida-PVP, campuran fisik furosemida-PVP dan kemudian dianalisa gugus fungsionalnya.

\section{Formulasi Tablet Furosemida}

Tabel 1. Formula tablet furosemida 


\begin{tabular}{|c|l|c|c|c|}
\hline \multirow{2}{*}{ No. } & \multirow{2}{*}{ Bahan } & \multicolumn{3}{|c|}{ Formula } \\
\cline { 3 - 5 } & & F.I (mg) & F.II (mg) & F.III (mg) \\
\hline 1. & Furosemida & - & 40 & 40 \\
\hline 2. & PVP & - & 10 & 20 \\
\hline 3. & Laktosa & - & 98 & 91 \\
\hline 4. & Amilum Manihot & - & 42 & 39 \\
\hline 5. & Alkohol 96\% & - & 4 & qs \\
\hline 6. & Talk:Mg (9:1) & - & 6 & 6 \\
\hline 7. & Amilum Manihot kering & - & & \\
& & & & \\
\end{tabular}

Keterangan : F.I adalah tablet furosemida generik.

Dengan formula tabel II dibuat tablet dengan perhitungan bahan untuk pembuatan sebanyak 300 tablet tiap formula dengan bobot masing-masing $200 \mathrm{mg}$. Formula I tablet Furosemide ${ }^{\circledR}$ generik digunakan sebagai pembanding.

\section{Pembuatan Tablet Furosemida}

Amylum manihot, laktosa dan dispersi padat dicampur hingga homogen, lalu ditambahkan sedikit demi sedikit alkohol $96 \%$ sampai diperoleh massa yang kompak yang ditandai dengan massa yang dikepal dan mudah dipatahkan.

Kemudian massa tersebut dibuat menjadi granul yaitu dengan cara mengayak pada mesh no.14, granul yang terbentuk dikeringkan dalam lemari pengering dengan suhu 40-60 ${ }^{\circ} \mathrm{C}$ sampai dicapai kekeringan yang diinginkan selama 10 menit, lalu diayak dengan ayakan mesh no.20/50. Granul yang diperoleh lalu diuji sifat alirnya, dan dicampur dengan bahan yang lain sampai homogen. Kemudian dengan menggunakan mesin cetak tablet granul dicetak menjadi tablet.

\section{Evaluasi Terhadap Sifat Fisik Granul :}
a. Waktu Alir
b. Sudut diam

\section{Evaluasi Terhadap Sifat Fisik Tablet :}

a. Keseragaman bobot.

b. Kekerasan

c. Kerapuhan(Friabilitas)

d. Waktu hancur tablet. 


\section{Analisis Data}

Hasil uji sifat fisik tablet dan disolusi dilakukan dengan pendekatan pustaka dan parameter yang telah ditetapkan di pustaka serta dilakukan pula uji statistika dengan menggunakan perangkat lunak SPSS dengan taraf kepercayaan 95\% untuk mengetahui formula yang terbaik sifat fisik dan disolusinya.

\section{Pembahasan}

\section{Analisis Interaksi Obat dengan Zat Pembawa PVP}

Untuk mengetahui interaksi antara furosemida dengan PVP maka dilakukan analisis menggunakan spektroskopi inframerah dari senyawa furosemida tunggal, PVP tunggal, dispersi padat furosemida-PVP 1: 0,5, serta campuran fisik furosemida-PVP dengan perbandingan yang sama. Interpretasi spektra inframerah ditekankan pada pergeseran pita-pita puncak, pola serta intensitas spektra pada daerah bilangan gelombang yang karakteristik pada masing-masing spektra. Pergeseran puncak dan bilangan gelombang yang penting dan karakteristik tersebut dapat dilihat pada tabel 2 .

Tabel 2. Karakteristik bilangan gelombang jenis vibrasi yang terpenting dalam pergeseran pola spektra

(Sastrohamidojo, 1992 dan Silverstein et al, 1986).

\begin{tabular}{|c|c|c|c|c|c|}
\hline \multirow[b]{2}{*}{ Gugus } & \multicolumn{5}{|c|}{ Bilangan puncak spektra inframerah $\left(\mathrm{cm}^{-1}\right)$} \\
\hline & PVP & Furosemida & $\begin{array}{c}\text { Campuran } \\
\text { fisik }\end{array}$ & Kompleks & Perubahan \\
\hline $\begin{array}{c}\text { Rentangan N- } \\
\mathrm{H} \text { amina } \\
\text { sekunder }\end{array}$ & - & $\begin{array}{c}3351 \text { (lemah, } \\
\text { tajam) }\end{array}$ & $\begin{array}{l}3301 \text { (lemah, } \\
\text { tajam) }\end{array}$ & $\begin{array}{c}3350 \\
\text { (lemah, } \\
\text { tajam) }\end{array}$ & $\begin{array}{c}\text { Bergeser } \\
\text { profil } \\
\text { berubah }\end{array}$ \\
\hline $\begin{array}{l}\text { Rentangan N- } \\
\text { H Sulfonamida }\end{array}$ & - & $\begin{array}{c}3284 \\
\text { (lemah, } \\
\text { tajam) }\end{array}$ & $\begin{array}{l}3285 \text { (lermah, } \\
\text { tajam) }\end{array}$ & $\begin{array}{c}3283 \\
\text { (lemah, } \\
\text { tajam) }\end{array}$ & $\begin{array}{l}\text { Bergeser, } \\
\text { profil } \\
\text { berubah }\end{array}$ \\
\hline $\begin{array}{c}\text { Rentangan C- } \\
\text { H } \\
\text { Alkana }\end{array}$ & $\begin{array}{c}2959 \\
\text { (lemah, } \\
\text { tajam) }\end{array}$ & - & $\begin{array}{c}2959 \text { (lemah, } \\
\text { tajam) }\end{array}$ & $\begin{array}{c}2954 \text { (lemah } \\
\text { tajam) }\end{array}$ & $\begin{array}{c}\text { Bergeser } \\
\text { profil } \\
\text { berubah }\end{array}$ \\
\hline $\mathrm{C}=\mathrm{O}$ & $\begin{array}{l}1649 \\
\text { (kuat, } \\
\text { tajam) }\end{array}$ & $\begin{array}{c}1672 \text { (kuat, } \\
\text { tajam) }\end{array}$ & $\begin{array}{c}1670 \text { (kuat, } \\
\text { tajam) }\end{array}$ & $\begin{array}{c}1669 \text { (kuat, } \\
\text { tajam ) }\end{array}$ & Tetap \\
\hline $\begin{array}{c}\text { Bengkokan N- } \\
\mathrm{H}\end{array}$ & - & $\begin{array}{c}1563 \text { dan } \\
1592 \text { (kuat, } \\
\text { tajam) }\end{array}$ & $\begin{array}{c}1564 \text { dan } \\
1592 \text { (lemah, } \\
\text { tajam }\end{array}$ & $\begin{array}{c}1563 \text { dan } \\
1592 \\
\text { (lemah, } \\
\text { tajam) }\end{array}$ & Tetap \\
\hline $\begin{array}{c}\text { Bengkokan } \\
\mathrm{CH}_{2}\end{array}$ & $\begin{array}{l}1463 \\
\text { (kuat, } \\
\text { tajam) }\end{array}$ & - & - & - & Hilang \\
\hline $\begin{array}{c}\text { Bengkokan C- } \\
\mathrm{N}\end{array}$ & $\begin{array}{c}1375 \\
\text { (lemah, } \\
\text { tajam) }\end{array}$ & - & - & - & Hilang \\
\hline
\end{tabular}




\begin{tabular}{|c|c|c|c|c|c|}
\hline $\begin{array}{l}\text { Rentangan } \\
\quad \mathrm{S}=\mathrm{O} \\
\text { Asimetrik }\end{array}$ & - & $\begin{array}{c}1143 \text { dan } \\
1323 \text { (kuat, } \\
\text { tajam) }\end{array}$ & $\begin{array}{c}1143 \text { dan } \\
1323 \text { (sedang, } \\
\text { tajam) }\end{array}$ & $\begin{array}{c}1142 \text { dan } \\
1322 \\
\text { (sedang, } \\
\text { tajam) }\end{array}$ & $\begin{array}{c}\text { Bergeser } \\
\text { profil } \\
\text { berubah }\end{array}$ \\
\hline
\end{tabular}

Pergeseran rentangan $\mathrm{S}=\mathrm{O}$ asimetrik furosemida terlihat pada kompleks bergeser ke kanan dan terjadi penurunan intensitas serapan pada campuran fisik dan kompleks. Gugus $\mathrm{C}=\mathrm{O}$ pada masing-masing spektra tidak menunjukkan pergeseran yang bermakna, sedangkan bengkokan $\mathrm{CH}_{2}$ dan $\mathrm{C}-\mathrm{N}$ pada PVP akan hilang. Pergeseran ini disebabkan terjadinya delokalisasi elektron karena ada interaksi antara molekul furosemida dan molekul PVP. Pada senyawa furosemida gugus $\mathrm{Cl}$ akan bermuatan positif karena mengalami delokalisasi elektron dan inti benzen bermuatan negatif . Di sisi lain, dengan adanya pasangan elektorn bebas pada atom N, pada inti pirolidon akan terjadi delokalisasi elektron ke atom $\mathrm{O}$ (elektronegatif kuat) gugus karbonil, sehingga elektron density inti pirolidon rendah dan bermuatan positif. Muatan positif dari inti pirolidon ini akan berinteraksi dengan muatan negatif dari inti benzen furosemida sehingga akan terjadi ikatan kompleks molekuler.

Tabel 3. Hasil Uji sifat Fisik tablet dari setiap Formula

\begin{tabular}{|c|c|c|c|c|c|}
\hline \multirow{2}{*}{$\begin{array}{c}\text { Parameter } \\
\text { Ujji }\end{array}$} & \multicolumn{5}{|c|}{ FORMULA } \\
\hline & F.I & F.II & F.III & Statistika & Keterangan \\
\hline $\begin{array}{c}\text { Keseragaman } \\
\text { Bobot (mg) }\end{array}$ & 169.7 & 210.0 & 214.6 & $\begin{array}{c}\text { Berbeda } \\
\text { bermakna }\end{array}$ & $\begin{array}{c}\text { Memenuhi } \\
\text { syarat }\end{array}$ \\
\hline $\begin{array}{l}\text { Kekerasan } \\
\text { Tablet (kg) }\end{array}$ & 6.8 & 5.9 & 7.2 & $\begin{array}{c}\text { Tidak } \\
\text { berbeda } \\
\text { bermakna }\end{array}$ & $\begin{array}{c}\text { Memenuhi } \\
\text { syarat }\end{array}$ \\
\hline Kerapuhan (\%) & 0.16 & 0.83 & 0.82 & $\begin{array}{c}\text { Tidak } \\
\text { berbeda } \\
\text { bermakna }\end{array}$ & $\begin{array}{l}\text { Memenuhi } \\
\text { syarat }\end{array}$ \\
\hline $\begin{array}{c}\text { Waktu Hancur } \\
\text { (menit) }\end{array}$ & 9.31 & 3.89 & 9.93 & $\begin{array}{c}\text { Berbeda } \\
\text { bermakna }\end{array}$ & $\begin{array}{l}\text { Memenuhi } \\
\text { syarat }\end{array}$ \\
\hline
\end{tabular}

\section{Kesimpulan}

Setelah dilakukan penelitian dapat diambil kesimpulan sebagai berikut:

1. Hasil analisis spektra inframerah dari PVP tunggal, furosemida tunggal, campuran fisik furosemida-PVP dan kompleks furosemida-PVP 1: $1 / 2$ didapatkan hasil bahwa ada interaksi kompleksasi antara keduanya. 
2. Pembentukkan kompleks furosemida dengan polivinilpirolidon (PVP) dapat menghasilkan tablet furosemida yang memuhi persyaratan sifat fisik tablet furosemida yang baik.

\section{B. Saran.}

1. Diharapkan untuk penelitian lebih lanjut perlu dilakukan optimasi formulasi tablet furosemida yang dibuat melalui pembentukkan kompleks dengan PVP.

2. Perlu dilakukan penelitian lebih lanjut tentang studi bioekivalensinya.

\section{DAFTAR PUSTAKA}

Anonim, 1979, Farmakope Indonesia, Edisi III, 6-8, 263, Departemen Kesehatan RI Jakarta.

Anonim, 1986 ${ }^{\mathrm{a}}$, Handbook of Pharmaceutical Excipient, 433, American Pharmaceutical Association, Washington.

Anonim, 1986 , Beberapa Aspek Pokok Pengujian Mutu Perbekalan Farmasi, Direktorat Jenderal Pemeriksaan Obat dan Makanan, Departemen Kesehatan RI, Japan International Cooperation Agency (JICA).

Anonim, 1995, Farmakope Indonesia, Edisi IV, 4-6, 400-402, 999-1000, 1083-1085. Departemen Kesehatan RI Jakarta.

Ansel, H.C., 1989, Pengantar Bentuk Sediaan Farmasi, Alih bahasa Farida Ibrahim , Edisi IV, 244-272, UI Press, Jakarta.

Bates, T.R. and Gibaldi, M.,1970, Gastrointestinal Absorbtion of Drug., Swarbrick.J, (ed) Current Concept in Pharmaceutical Sciences Biopharmaceutic $1^{\text {st }}$ Edition, 58-99, LEA and FEBIGER Philadelpia.

Cartensen, J.T., 1973, Theory of Pharmaceutical Systems, Vol 2, 221-224, Academic Press, New York. 
Cartensen, J.T., 1977, Pharmaceutic of Solids and Solid Dosage Forms, 209-214, Wiley, Intercinnce Publication John Wiley and Sons, New York.

Chiou, W.L., and Riegelman, S., 1971, Pharmaceutuical Application of Solid Dispersion System, J. Pharm. Sci., 60 (9), 1281-1301.

Fonner, D.E., Anderson, N.R., and Banker, G.S., 1981, Granulation and Tablet Characteristic, in Lieberman, H.A., Lachman, L., (eds) Pharmaceutical Dosage Form, Tablets, Vol 2, 185, 242-248, Marcel Dekker Inc., New York.

Fudholi, A., 1983, Metodologi Formulasi dalam Kompresi Direk, Medika, No.7, , 585593, Gabungan Perusahaan Farmasi Indonesia, Jakarta.

Gandjar, I.G., 1991, Kimia Analisis Instrumental, 15-27, Fakultas Farmasi UGM, Yogyakarta.

Gibaldi, M., and Feldman, S., 1970, Mechanis of Surfactant effect on drug absorbtion, J.Pharm Sci, 59,579-589.

Gunsel, W.C., and Kanig J.L., 163 lets in Lachman, L., Lieberman, H.A., and Kanig, J.L., (Eds) The Theory and Practice of Industial Pharmacy, $2^{\text {nd }}$ edition, 328-331, LEA and FEBIGER, Philadelphia.

Indariyani, K., 2001, Peningkatan kelarutan furosemida melalui pembentukan Kompleks dengan PEG-4000, Skripsi, Fakultas Farmasi Universitas Ahamad Dahlan, Yogyakarta.

Khan, K.A.,1975, The Concept of Dissolution Efficiency, J.Pharm, Pharmacol., 27, 4849. 
Lachman, L., Lieberman, H.A., dan Kanig, J.L., 1976, Bentuk sediaan Berkesinambungan dalam Teori dan Praktek Industri Farmasi, Edisi III, diterjemahkan oleh Siti Suyatmi dan Iis Aisyah, 430-431,UI Press, Jakarta.

Martin, A.N., Swarbrick, J., and Cammarata, A., 1983, Farmasi Fisika, diterjemahkan oleh Yoshita, Edisi IV, 314-346 UI Press, Jakarta.

Novtyana, T., 2001, Peningkatan kecepatan disolusi intrinsik furosemida melalui pembentukan dispersi padat dengan PEG-4000, Skripsi, Fakultas Farmasi Universitas Ahmad Dahlan, Yogyakarta.

Parrott, E.L., 1971, Pharmaceutical Technology Fundamental Pharmaceutics, $3^{\text {rd. }}$ Ed, 73-83, Burgess Publishing Company, Minneapolis.

Sastrahamidjojo, H., Sardjoko (editor), 1992, Spektroskopi Inframerah, 17-46, Liberty, Yogyakarta.

Shargel, L dan Yu, A.B.C., 1985, Biofarmasetika dan Farmakokinetika Terapan, Edisi II, 95-100, 445-446, 452-477, diterjemahkan Fasich dan Siti Syamsiah, University Airlangga Press, Surabaya.

Sheth, B.B., Bandellin, and F.J Shangraw, K.F, 1980, Compressed Tablet. In Lieberman , H.A., Lachman L., (eds) Pharmaceutical Dosage Form : Tablets Vol 1, 109-120 Marcel Dekker Inc, New York.

Silverstein, Basler dan Morril, 1986, Penyidikkan Spektrofotometrik Senyawa Organik, diterjemahkan oleh : Hartomo, A.J., Purba, A.V., Edisi 4, 95-114, Erlangga, Jakarta.

Syukri, Y., 2001, Peningkatan kelarutan, disolusi dan ketersediaan hayati furosemida melalui pembentukan dispersi padat, Tesis, Fakultas Farmasi Universitas Gadjah Mada., Yogyakarta. 
Villiers, M.M., Liebenberg, W., Malan, S.F., and Gieber, J.J., 1999, The Dissolution and Complexing Properties of Ibuprofen and Ketoprofen when Mixing with NMetylglucamine, Drug-Dev. Ind. Pharm., 25(8), 967-972.

Voigt, R., 1971, Buku Pelajaran Teknologi Farmasi, alih bahasa Soendani Noerono Soewandi, 165-202, Gadjah Mada University Press, Yogyakarta.

Wagner, J.G., Taylor, P.W., 1969, Interpretation of Percent Dissolved-Time Plots Derived from In Vitro Testing of Conceptional Tablets and Capsules, $J$ Pharm. Sci., 58, 10. 